\title{
ALAN KNIGHT Y SU OBRA SOBRE LA REVOLUCIÓN MEXICANA
}

\author{
ALAN KNIGHT, LA REVOLUCIÓN MEXICANA, \\ MÉXICO, EDITORIAL GRIJALBO, 1996, \\ TRADUCCIÓN DE LUIS CORTEZ BARGALLÓ \\ DE LA EDICIÓN DE CAMBRIDGE UNIVERSITY PRESS, \\ GRAN BRETAÑA, 1986. \\ VOLUMEN I: PORFIRISTAS, LIBERALES Y CAMPESINOS; \\ VOLUMEN II: CONTRARREVOLUCIÓN Y RECONSTRUCCIÓN.
}

(3)

Invitado por el Departamento de Historia de la Universidad Autónoma de Aguascalientes, el Dr. Alan Knight, profesor del Sanit Antony College, de la Universidad de Oxford, en Gran Bretaña, asistió como invitado especial a una mesa de presentación de su libro La Revolución Mexicana, que se llevó a cabo en el Centro Cultural Los Arquitos el 14 de abril de 1997. Con el permiso de sus autores, publicamos los comentarios de Vicior M. González Esparza, Robert Curley y Francisco Javier Meyer, quienes amablemente aceptaron participar en esa reunión. 
